\title{
Synthetic surfactant containing SP-B and SP-C mimics is superior to single-peptide formulations in rabbits with chemical acute lung injury
}

Background. Chemical spills are on the rise and inhalation of toxic chemicals may induce chemical acute lung injury (ALI)/acute respiratory distress syndrome (ARDS). Although the pathophysiology of ALI/ARDS is well understood, the absence of specific antidotes besides has limited the effectiveness of therapeutic interventions. Objectives. Surfactant inactivation and formation of free radicals are important pathways in (chemical) ALI. We tested the potential of lipid mixtures with advanced surfactant protein B and C (SP-B and C) mimics to improve oxygenation and lung compliance in rabbits with lavage- and chemical-induced ALI/ARDS. Methods. Ventilated young adult rabbits underwent repeated saline lung lavages or underwent intratracheal instillation of hydrochloric acid to induce ALI/ARDS. After establishment of respiratory failure rabbits were treated with a single intratracheal dose of $100 \mathrm{mg} / \mathrm{kg}$ of synthetic surfactant composed of $3 \%$ Super Mini-B (S-MB), a SP-B mimic, and/or SP-C33 UCLA, a SP-C mimic, in a lipid mixture (DPPC:POPC:POPG 5:3:2 by weight), the clinical surfactant Infasurf®, a bovine lung lavage extract with SP-B and C, or synthetic lipids alone. End-points consisted of arterial oxygenation, dynamic lung compliance, and protein and lipid content in bronchoalveolar lavage fluid. Potential mechanism of surfactant action for S-MB and SP-C33 UCLA were investigated with captive bubble surfactometry (CBS) assays. Results. All three surfactant peptide/lipid mixtures and Infasurf equally lowered the minimum surface tension on CBS, and also improved oxygenation and lung compliance. In both animal models, the two-peptide synthetic surfactant with S-MB and SPC33 UCLA led to better arterial oxygenation and lung compliance than single peptide synthetic surfactants and Infasurf. Synthetic surfactants and Infasurf improved lung function further in lavage- than in chemical-induced respiratory failure, with the difference probably due to greater capillary-alveolar protein leakage and surfactant dysfunction after $\mathrm{HCl}$ instillation than following lung lavage. At the end of the duration of the experiments, synthetic 
surfactants provided more clinical stability in ALI/ARDS than Infasurf, and the protein content of bronchoalveolar lavage fluid was lowest for the two-peptide synthetic surfactant with S-MB and SP-C33 UCLA. Conclusion. Advanced synthetic surfactant with robust SP-B and SP-C mimics is better equipped to tackle surfactant inactivation in chemical ALI than synthetic surfactant with only a single surfactant peptide or animal-derived surfactant. 
1 Synthetic surfactant containing SP-B and SP-C mimics is superior to single-peptide

2

3

4 Frans J. Walther ${ }^{1,2}$, José M. Hernández-Juviel ${ }^{1}$, Larry M. Gordon ${ }^{1}$, Alan J. Waring ${ }^{3,4,5}$

5

$6 \quad$ 'Department of Pediatrics, Division of Medical Genetics, Los Angeles Biomedical Research

7 Institute, Harbor-UCLA Medical Center, Torrance, California

$8 \quad{ }^{2}$ Department of Pediatrics, David Geffen School of Medicine, University of California Los

9 Angeles

$10{ }^{3}$ Department of Medicine, Division of Molecular Medicine, Los Angeles Biomedical Research

11 Institute, Harbor-UCLA Medical Center, Harbor-UCLA Medical Center, Torrance, California

$12{ }^{4}$ Department of Medicine, David Geffen School of Medicine, University of California Los

13 Angeles

$14{ }^{5}$ Department of Physiology \& Biophysics, School of Medicine, University of California Irvine,

15 California

16

17 Short title: Synthetic surfactant and chemical acute lung injury

23 Funding: The authors gratefully acknowledge the financial support of the National Institutes of 24 Health through grant R01ES015330. NIH had no role in the design and conduct of the study, in 
25 the collection, analysis, and interpretation of the data, and in the preparation, review, or approval 26 of the manuscript.

27 


\section{ABSTRACT}

29 Background. Chemical spills are on the rise and inhalation of toxic chemicals may induce

30 chemical acute lung injury (ALI)/acute respiratory distress syndrome (ARDS). Although the

31 pathophysiology of ALI/ARDS is well understood, the absence of specific antidotes has limited

32 the effectiveness of therapeutic interventions.

33 Objectives. Surfactant inactivation and formation of free radicals are important pathways in

34 (chemical) ALI. We tested the potential of lipid mixtures with advanced surfactant protein B and

$35 \mathrm{C}$ (SP-B and C) mimics to improve oxygenation and lung compliance in rabbits with lavage- and 36 chemical-induced ALI/ARDS.

37 Methods. Ventilated young adult rabbits underwent repeated saline lung lavages or underwent

38 intratracheal instillation of hydrochloric acid to induce ALI/ARDS. After establishment of

39 respiratory failure rabbits were treated with a single intratracheal dose of $100 \mathrm{mg} / \mathrm{kg}$ of synthetic

40 surfactant composed of 3\% Super Mini-B (S-MB), a SP-B mimic, and/or SP-C33 UCLA, a SP-C

41 mimic, in a lipid mixture (DPPC:POPC:POPG 5:3:2 by weight), the clinical surfactant Infasurf®,

42 a bovine lung lavage extract with SP-B and C, or synthetic lipids alone. End-points consisted of

43 arterial oxygenation, dynamic lung compliance, and protein and lipid content in bronchoalveolar

44 lavage fluid. Potential mechanisms of surfactant action for S-MB and SP-C33 UCLA were

45 investigated with captive bubble surfactometry (CBS) assays.

46 Results. All three surfactant peptide/lipid mixtures and Infasurf equally lowered the minimum

47 surface tension on CBS, and also improved oxygenation and lung compliance. In both animal

48 models, the two-peptide synthetic surfactant with S-MB and SP-C33 UCLA led to better arterial

49 oxygenation and lung compliance than single peptide synthetic surfactants and Infasurf. Synthetic

50 surfactants and Infasurf improved lung function further in lavage- than in chemical-induced

51 respiratory failure, with the difference probably due to greater capillary-alveolar protein leakage

52 and surfactant dysfunction after $\mathrm{HCl}$ instillation than following lung lavage. At the end of the 
53 duration of the experiments, synthetic surfactants provided more clinical stability in ALI/ARDS

54 than Infasurf, and the protein content of bronchoalveolar lavage fluid was lowest for the two-

55 peptide synthetic surfactant with S-MB and SP-C33 UCLA.

56 Conclusion. Advanced synthetic surfactant with robust SP-B and SP-C mimics is better equipped

57 to tackle surfactant inactivation in chemical ALI than synthetic surfactant with only a single

58 surfactant peptide or animal-derived surfactant.

59

60 Keywords: synthetic surfactant, surfactant protein B, surfactant protein C, acute lung injury, lung

61 lavage, hydrochloric acid, ventilated rabbits, oxygenation, lung compliance, captive bubble

62 surfactometry 
INTRODUCTION

Acute lung injury (ALI) and acute respiratory distress syndrome (ARDS) are

65

66

67

characterized by severe hypoxic respiratory failure and poor lung compliance, mostly caused by lung injury due to pneumonia, aspiration, sepsis and trauma (Bernard et al., 1994; Matthay, Ware \& Zimmerman, 2012). Despite advances in respiratory support, morbidity and mortality of ALI/ARDS continue to be elevated due to a lack of efficient therapeutic modalities. Surfactant replacement therapy has long been considered to be a logical pharmacologic approach as the poor lung compliance in ALI/ARDS is associated with surfactant deficiency and inactivation.

However, whereas animal-derived surfactant preparations are highly active in preventing and treating respiratory distress syndrome (RDS) in premature infants (Polin \& Carlo, 2014), their efficacy in pediatric and adult patients with ALI/ARDS has been utterly disappointing (Willson et al., 2005; Czaja, 2007). After recombinant SP-C based surfactant (Venticute®, Nycomed GmbH, Konstanz, Germany) failed to improve oxygenation in a recent randomized clinical trial because of insufficient surface activity (Spragg et al., $2004 \& 2011$ ), doubts have risen about the rationale for exogenous surfactant treatment in ALI/ARDS (Brower \& Fessler, 2011; Dushianthan et al., 2012).

Chemical spills are frequently in the news and the lung has come under attack from chemical spills and even bioterrorism (Maynard \& Tetley, 2004; White \& Martin, 2010). The lung's response to inhalation injury of toxic chemicals (chemical ALI) ranges from reactive airways dysfunction syndrome (RADS) to ALI/ARDS with possible fatal outcome (Maynard \& Tetley, 2004; Gorguner et al., 2004; White \& Martin, 2010). Depending on the toxicant, dose and host factors, cell damage (necrosis or apoptosis) will erode the capillary-alveolar barrier and increase the "leakage" of plasma proteins and water into the interstitium and ultimately into the alveolar spaces. Proteinaceous alveolar edema inactivates lung surfactant and critically affects lung function by reducing lung compliance. Reaction of toxicants with double bonds in 
unsaturated lipids in cell membranes and lung surface fluids can start a cascade of free radical reactions that further damages cells. Peroxides and carbonyls produced in these reactions may

90 elicit inflammation in the lung via the prostaglandin and leukotriene cascades and magnify and

91 disseminate the toxic injury. The debris of damaged cells and a wide variety of mediators, such as

92 cytokines and chemokines, released by airway epithelium, will attract macrophages and other

93 lung matrix cells and activate various cell surface adhesion molecules, i.e. integrins, on the

94 vascular and respiratory surface. Although the pathophysiology of toxic inhalation injury is well

95 understood (Matthay, Ware \& Zimmerman, 2012), specific antidotes to toxic inhalants are not yet

96 available. A potential approach towards chemical ALI, and possibly ALI/ARDS in general, may

97 be offered by the use of a new generation of synthetic surfactant that effectively counteracts

98 surfactant inactivation due to vascular leakage of serum proteins, acute inflammation and

99 oxidative stress (Walther et al., 2000, 2007 \& 2010; Curstedt, Calkovska \& Johansson, 2013;

100 Johansson et al., 2003).

101 Native lung surfactant is a complex mixture that plays a pivotal role in normal breathing

102 because of its ability to reduce alveolar surface tension to low values and consists of $\sim 80 \%$

103 phospholipids, 10\% neutral lipids and 10\% proteins (Notter, 2000). Its biophysical activity

104 depends uniquely on the hydrophobic surfactant proteins B (SP-B) and C (SP-C) (Goerke, 1998;

105 Johansson, 1998; Whitsett \& Weaver, 2002). SP-B is a 79 amino acid, lipid-associating monomer

106 (MW $\sim 8.7 \mathrm{kDa}$ ) in humans that is found in the lung as a covalently linked homodimer. Each SP-

107 B monomer consists of 4-5 $\alpha$-helices with three intramolecular disulfide bridges (i.e., Cys-8 to

108 Cys-77, Cys-11 to Cys-71 and Cys-35 to Cys-46) (Johansson, Curstedt \&, Jornvall, 1991), and

109 belongs to the saposin protein superfamily. Surfactant protein C (SP-C) is a short (35 amino

110 acids; MW of $4.2 \mathrm{kDa}$ in humans) protein that is highly enriched in valine, leucine and isoleucine

111 residues, making it much smaller and more hydrophobic than SP-B. The sequence of porcine SP-

112 C (i.e., $\mathrm{NH}_{2}-$ RIPCCPVNLKRLLVVVVVVVLVVVVIVGALLMGL-COOH), which is highly 
113 homologous to that of human SP-C, has an N-terminus with a pair of vicinal Cys residues linked

114 to palmitoyl moieties via thioester bonds, thereby producing a true "proteolipid" (Curstedt et al.,

115 1990). These palmitoyl groups are adjacent to a short polar, $N$-terminal segment characterized by

116 cationic residues such as lysine and arginine. The N-terminal region of SP-C (residues 1-8) is

117 followed by an extremely hydrophobic polyvaline sequence with residues 9 to 34 forming a

118 stable $\alpha$-helix in the mid- and C-terminal regions (PDB accession code: 1SPF). When

119 incorporated into lipids, Fourier transform infrared (FTIR) spectroscopy also showed that

120 dipalmitoylated SP-C is principally $\alpha$-helical, with its long molecular helix axis parallel to the

121 phospholipid acyl chains (Pastrana, Maulone \& Mendelsohn, 1991; Vandenbussche et al., 1992).

122 Additional results indicated that high surfactant activities for SP-C peptides were closely

123 correlated with enhanced $\alpha$-helicity (Johansson et al., 1995; Wang et al., 1996; Johansson, 1998).

124 Recent work by our group on synthetic SP-B peptides and that of Johansson and Curstedt

125 (Karolinska Institute, Stockholm, Sweden) on synthetic SP-C peptides has led to the creation of

126 highly surface active peptide mimics of SP-B and SP-C, i.e. Super Mini-B (S-MB) (Walther et

127 al., 2010) and SP-C33 (Johansson et al., 2003). S-MB is a 41-residue SP-B mimic (primary

128 sequence $\mathrm{NH}_{2}$-FPIPLPYCWLCRALIKRIQAMIPKGGRMLPQLVCRLVLRCS-COOH) that

129 reproduces the topology of the $\mathrm{N}$ - and $\mathrm{C}$-terminal domains of SP-B by joining the N-terminal

130 (residues 1-25) and C-terminal (residues 63-78) $\alpha$-helices with a custom $\beta$-turn that replaces SP-B

131 residues 26-62. Thus, S-MB is a 'short-cut' version of SP-B, in which the neighboring N- and C-

132 terminal $\alpha$-helices adopt a helix-turn-helix motif that is cross-linked by disulfide bridges at Cys- 8

133 to Cys-40 and Cys-11 to Cys-34. S-MB has been shown to be highly surface active in vitro and in

134 vivo, and this may be partially due to its positively charged amphipathic helices binding to

135 anionic surfactant lipids (Waring et al. , 2005; Walther et al., 2010). The function of SP-C is

136 highly dependent on preservation of its transmembrane $\alpha$-helix in lipids and targeted amino-acid

137 replacements have enabled the development of SP-C33, an SP-C mimic with enhanced $\alpha$-helicity 
138 in lipids and surface activities, resembling those of native SP-C (Johansson et al., 2003; Almlén

139 et al., 2010). Specifically, the 33-residue SP-C33 (primary sequence, $\mathrm{NH}_{2}-$

140 IPSSPVHLKRLKLLLLLLLLILLLILGALLMGL-COOH) was adapted from the native porcine

141 sequence (see above), in which the vicinal palmitoylcysteines were replaced by serines, ten valine

142 residues were swapped with leucines and a cationic amino acid was moved from the N-terminus

143 closer to the other positively charged residues (Johansson et al., 2003; Almlén et al., 2010).

144 Surface activity is not only dependent on the quantity and quality of surfactant peptides in lipid

145 mixtures, but also on the lipid constituents themselves, their interaction with surfactant peptides,

146 and the viscosity of peptide/lipid mixtures (Tanaka et al., 1986; Walther et al., 2005; Seurynck-

147 Servoss et al., 2007). Recent research has led us to formulate advanced SP-B and SP-C peptides

148 in a lipid mixture that mimics the composition of native lung surfactant (Notter, 2000; Walther et

149 al., 2005).

150 Although in vitro methods can rapidly provide information about surface activity of

151 experimental surfactant preparations, whole-animal studies are still necessary to test potential

152 treatment modalities in chemical lung injury. Surfactant deficiency induced by repeated saline

153 lung lavages (Ito et al., 1996; Walther et al., 1998) and surfactant dysfunction induced by

154 intratracheal instillation of hydrochloric acid (Chiumello, Pristine \& Slutsky, 1999; Brackenbury

155 et al., 2001) in rats and rabbits are established animal models for ALI/ARDS. Both models allow

156 serial measures of arterial blood gases and represent a relatively pure state (over the first 6-9

157 hours or so) of surfactant dysfunction in animals with mature lungs. In this study, we tested the

158 potential of advanced synthetic surfactant preparations to stabilize and improve lung function in

159 adult rabbits with ALI/ARDS induced by lung lavages and chemical exposure.

160

161 MATERIALS AND METHODS

162 Materials 
164 high performance liquid chromatography (HPLC) solvents from Fisher Chemical Co. (Pittsburgh, 165 PA), and all other chemicals from Sigma Chemical Co. (St. Louis, MO) and Aldrich Chemical

166 Co. (Milwaukee, WI). Dipalmitoylphosphatidylcholine (DPPC), palmitoyloleoyl-

167 phosphatidylcholine (POPC) and palmitoyloleoylphosphatidylglycerol (POPG) were from Avanti

168 Polar Lipids (Alabaster, AL). The clinical surfactant Infasurf® (Calfactant), a bovine lung lavage

169 extract, was a generous gift of Ony Inc (Amherst, NY). Young adult New Zealand White rabbits,

170 weighing 1.0-1.3 kg, were obtained from I.F.P.S. (Norco, CA).

172 Synthesis and Characterization of Surfactant Peptides

173 S-MB peptide (Walther et al., 2010) and SP-C33 (Johansson et al., 2003) were

174 synthesized on a Symphony Multiple Peptide Synthesizer (Protein Technologies, Tucson, AZ)

175 with standard FMoc chemistry (Walther et al., 2010). Crude peptides were purified by reverse

176 phase HPLC, molecular weights of the peptides were verified by MALDI-TOF, and $\alpha$-helicity

177 was determined by FTIR spectroscopy. Disulfide connectivities for S-MB (i.e., Cys-8 to Cys-40

178 and Cys-11 to Cys-34) were confirmed by mass spectroscopy of enzyme-digested fragments

179 (trypsin and chymotrypsin digestion) (Walther et al., 2010). We renamed the SP-C33 analog

180 produced in our lab as SP-C33 UCLA to distinguish it from SP-C33 made by Chiesi

181 Pharmaceutici SpA (Parma, Italy).

182

\section{Surfactant Preparations}

184 Synthetic surfactant preparations were formulated by mixing synthetic phospholipids, 185 consisting of 5:3:2 (weight ratio) DPPC:POPC:POPG, with 3\% S-MB, 3\% SP-C33 UCLA, or $1861.5 \%$ S-MB $+1.5 \%$ SP-C33 UCLA. All surfactant preparations were formulated at a 187 concentration of $35 \mathrm{mg}$ phospholipids/ml. The composition of the synthetic phospholipid mixture 
188 was based on the lipid composition of native lung surfactant (Notter, 2000; Walther et al, 2005).

189 Infasurf, which contains $35 \mathrm{mg} / \mathrm{ml}$ of phospholipids with $1.5 \%$ proteins, of which $0.8 \%$ is SP-B,

190 was used as positive control and synthetic lipids alone as negative control.

192 Captive Bubble Surfactometry

193 Adsorption and dynamic surface tension lowering ability of all surfactant preparations

194 were measured with a captive bubble surfactometer at physiological cycling rate, area

195 compression, temperature, and humidity (Walther et al., 2010). We routinely analyze surfactant

196 samples of $1 \mu \mathrm{l}(35 \mathrm{mg}$ phospholipids/ml) in the captive bubble surfactometer and perform all

197 measurements in quadruplicate.

198

199

Animal studies

The animal studies were reviewed and approved by the Institutional Animal Care and Use

201 Committee of the Los Angeles Biomedical Research Institute at Harbor-UCLA Medical Center

202 (Research Project \# 12507). All procedures and anesthesia were in accordance with the American

203 Veterinary Medical Association (AMVA) Guidelines.

204

205

Young adult New Zealand white rabbits (weight 1.0-1.3 kg) received anesthesia with 50 $\mathrm{mg} / \mathrm{kg}$ of ketamine and $5 \mathrm{mg} / \mathrm{kg}$ of acepromazine intramuscularly prior to placement of a venous

207 line via a marginal ear vein. After intravenous administration of $1 \mathrm{mg} / \mathrm{kg}$ of diazepam and 0.2

$208 \mathrm{mg} / \mathrm{kg}$ of propofol, a small incision was made in the skin of the anterior neck for placement of an 209 endotracheal tube and a carotid arterial line. After placement of the endotracheal tube, muscle 210 paralysis was induced with intravenous pancuronium $(0.1 \mathrm{mg} / \mathrm{kg})$. During the ensuing duration of

211 mechanical ventilation, anesthesia was maintained by continuous intravenous administration of 3

$212 \mathrm{mg} / \mathrm{kg} / \mathrm{h}$ of propofol and intravenous dosages of $1 \mathrm{mg} / \mathrm{kg}$ of diazepam as needed; muscle 
213 paralysis was maintained by hourly intravenous administration of $0.1 \mathrm{mg} / \mathrm{kg}$ of pancuronium.

214 Heart rate, arterial blood pressures and rectal temperature were monitored continuously

215 (Labchart® Pro, ADInstruments Inc., Colorado Springs, CO, USA). Respiratory function was

216 followed by measurements of arterial $\mathrm{pH}$ and blood gases and dynamic lung compliance at 15

217 min intervals. Dynamic lung compliance was calculated by dividing tidal volume/kg body weight

218 by changes in airway pressure (peak inspiratory pressure minus positive end-expiratory pressure)

$219\left(\mathrm{ml} / \mathrm{kg} / \mathrm{cm} \mathrm{H}_{2} \mathrm{O}\right)$. Maintenance fluid was provided by a continuous infusion of Lactated Ringer's 220 solution at a rate of $10 \mathrm{ml} / \mathrm{kg} / \mathrm{h}$.

221 After stabilization on the ventilator, lung injury was induced by saline lung lavage or

222 intratracheal administration of hydrogen chloride $(\mathrm{HCl})$. Lung lavaging results in loss of active

223 surfactant, whereas $\mathrm{HCl}$ instillation leads to epithelial and endothelial damage, lung hemorrhages

224 and copious edema formation resulting in surfactant dysfunction. When the partial pressure of

225 oxygen in arterial blood $\left(\mathrm{PaO}_{2}\right)$ was $>500$ torr at a peak inspiratory pressure $<15 \mathrm{~cm}_{2} \mathrm{O}$ in

$226100 \%$ oxygen $\left(\mathrm{FiO}_{2}=1.0\right)$, the rabbits underwent repeated saline lung lavages until the $\mathrm{PaO}_{2}$

227 dropped below 100 torr (average 3 lavages of $30 \mathrm{ml}$ of normal saline, temperature $37^{\circ} \mathrm{C}$ ) or

228 received intratracheal $\mathrm{HCl}$ until the $\mathrm{PaO}_{2}$ dropped below 200 torr (average 2 doses of $1.5 \mathrm{ml} / \mathrm{kg}$

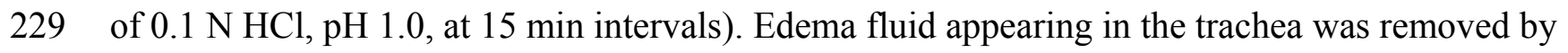

230 suctioning. When the $\mathrm{PaO}_{2}$ was stable at $<100$ torr in lavaged animals $(\mathrm{n}=39)$ or the $\mathrm{PaO}_{2} / \mathrm{FiO}_{2}$

231 ratio had reached stable values $<200$ torr $\left(\mathrm{PaO}_{2} / \mathrm{FiO} 2<40 \%\right.$ of pretreatment values $)$ within 30

232 min in HCl-exposed animals ( $\mathrm{n}=40$ ), an experimental or positive (Infasurf) or negative (synthetic

233 lipids alone) control surfactant mixture was instilled into the trachea at a dose of $100 \mathrm{mg} / \mathrm{kg}$ body

234 weight and a concentration of $35 \mathrm{mg} / \mathrm{ml}$. Group size was 7-9 in the lavaged and 8 in the $\mathrm{HCl}-$

235 exposed rabbits. All rabbits were ventilated using a Harvard volumecontrolled animal ventilator

236 (tidal volume $7.5 \mathrm{ml} / \mathrm{kg}$, positive end-expiratory pressure of $3 \mathrm{~cm} \mathrm{H} \mathrm{H}_{2} \mathrm{O}$, inspiratory/ expiratory

237 ratio of $1: 2,100 \%$ oxygen, and a respiratory rate to maintain the $\mathrm{PaCO}_{2}$ at $\sim 40 \mathrm{mmHg}$ ). Airway 
238 flow and pressures and tidal volume were monitored continuously with a pneumotachograph

239 connected to the endotracheal tube and a pneumotach system (Hans Rudolph Inc., Kansas City,

240 MO, USA). Animals were sacrificed $2 \mathrm{~h}$ after surfactant administration with an overdose of

241 pentobarbital. End-points were gas exchange (arterial $\mathrm{pH}, \mathrm{PaCO}_{2}$ and $\mathrm{PaO}_{2}$ ), pulmonary

242 mechanics (dynamic lung compliance), and bronchoalveolar lavage fluid proteins and lipids.

243

244 Protein and lipid measurements of bronchoalveolar lavage fluid (BALF)

245 Protein and lipid measurements of bronchoalveolar lavage fluid (BALF) collected during

246 the first lung lavage with $30 \mathrm{ml}$ of normal saline to induce surfactant deficiency (lavaged rabbits

247 only) and the first postmortem lavage (both lavaged and HCl-treated rabbits) are shown in Table

248 1. Protein was measured using the Lowry assay with human albumin as a standard. Phospholipids

249 were measured by extracting BALF samples in chloroform:methanol 2:1 v:v (1 ml of BALF +4

$250 \mathrm{ml}$ chloroform:methanol), applying the extract to the Fourier transform infrared-attenuated total

251 reflection (FTIR-ATR) plate and drying it before taking a spectrum (Goormaghtigh, Cabiaux \&

252 Ruysschaert, 1990).

253

254 Data analysis

255 Data are expressed as means \pm standard error (SEM). Statistical differences were

256 estimated using t-tests and analyses of variance (ANOVA). Student's t-test was used for

257 comparisons versus control values. Between groups comparisons at various time-points were

258 done by one-way ANOVA and time courses were analyzed with one-way repeated measure

259 ANOVA. A p value $<0.05$ was considered to indicate a significant difference.

260

261 RESULTS 
263 control) all had very high surface activity in captive bubble experiments and reached minimum 264 surface tension values $\leq 1 \mathrm{mN} / \mathrm{m}$ during each of ten consecutive cycles of dynamic cycling (rate

265 of 20 cycles/min, Figure 1). Lipids alone (negative control) reached significantly higher

266 minimum surface tension values of $16 \mathrm{mN} / \mathrm{m}(\mathrm{p}<0.001)$ than the one- and two peptide/lipid

267 mixtures and Infasurf. Therefore, the relative order for the surfactant activities determined with

268 captive bubble surfactometry for the various preparations were as follows: S-MB surfactant $\sim$ SP-

269 C33 UCLA surfactant $\sim$ S-MB + SP-C33 UCLA surfactant $\sim$ Infasurf $>>$ Lipids alone.

In the surfactant-deficiency model, induced by repeated lung lavages in young adult

271 rabbits, intratracheal instillation of surfactants with S-MB and/or SP-C33 UCLA and Infasurf

272 quickly improved oxygenation and lung compliance, and continued to be biologically active until

273 the end of the experimental period (Figure 2). S-MB was more active than SP-C33 UCLA, but

274 there was an additive effect of SP-C33 UCLA on S-MB function. The oxygenation and dynamic

275 compliance curves obtained for Infasurf were close to those of S-MB surfactant. Instillation of

276 "Lipids alone" had minimal effects on arterial oxygenation or compliance. The relative order of

277 pulmonary activities for the various surfactant preparations in terms of both oxygenation and

278 compliance was as follows: S-MB + SP-C33 UCLA surfactant $>$ S-MB surfactant $\sim$ Infasurf $>$

279 SP-C33 UCLA surfactant $>>$ Lipids alone. The differences in oxygenation and compliance

280 between S-MB + SP-C33 UCLA surfactant and S-MB, SP-C33 UCLA and Infasurf were

281 statistically significant starting at $90 \mathrm{~min}$ after surfactant instillation, $(\mathrm{p}<0.01)$ (Figure 2).

282 In the surfactant-dysfunction model, induced by one or more intratracheal instillations of

$283 \mathrm{HCl}$ in young adult rabbits, all peptide/lipid mixtures and Infasurf were less effective in

284 improving oxygenation and lung compliance than in the lung lavage model (Figures 2 and 3).

285 Oxygenation and lung compliance continued to deteriorate after intratracheal instillation of

286 synthetic lipids alone. Infasurf outperformed the peptide/lipid mixtures during the first $45 \mathrm{~min}$ 
287 after intratracheal instillation, but then started to lose activity as shown by deteriorating

288 oxygenation and lung compliance and its surfactant activity was surpassed by the consistent

289 performance of the peptide/lipid mixtures thereafter. The two-peptide surfactant mixture of S-MB

290 and SP-C33 UCLA in DPPC:POPC:POPG lipids finally outperformed the one-peptide mixtures

291 with SMB or SP-C33 UCLA and Infasurf, though they all succeeded in stabilizing and improving

292 lung function after induction of chemical lung injury for the duration of the experiment.

293 Instillation of synthetic lipids alone led to a continuous further deterioration of arterial

294 oxygenation and lung compliance. The relative order of pulmonary activity in terms of both

295 oxygenation and compliance ( $\geq 90$ min) was given as: S-MB + SP-C33 UCLA surfactant $>$ S-MB

296 surfactant $\sim$ SP-C33 UCLA surfactants $\sim$ Infasurf $>>$ Lipids alone. The differences in arterial

297 oxygenation and lung compliance between the S-MB + SP-C33 UCLA surfactant and S-MB

298 surfactant $\sim$ SP-C33 UCLA surfactants $\sim$ Infasurf were statistically significant starting at 90 min

299 after surfactant instillation $(\mathrm{p}<0.01)$ (Figure 3).

$300 \quad$ Average $( \pm$ SEM) protein content of BALF (Table 1) in the total group of lavaged animals

$301(\mathrm{n}=39)$ increased almost 10 -fold from $286 \pm 10 \mu \mathrm{g} / \mathrm{ml}$ in the first $30 \mathrm{ml}$ lavage to induce

302 surfactant-deficiency to $2,776 \pm 132 \mu \mathrm{g} / \mathrm{ml}$ in the first postmortem lavage. This increase was least

303 for S-MB+SP-C33 UCLA and S-MB surfactant and highest for synthetic lipids alone. Protein

304 content of BALF in the first postmortem lavage of the $40 \mathrm{HCl}$-instilled rabbits was higher than in

305 the 39 lavaged rabbits $(3,514 \pm 143$ vs $2,776 \pm 137, \mathrm{p}<0.001)$. Rabbits from the HCl group treated

306 with S-MB+SP-C33 UCLA had the lowest and rabbits treated with lipids only had the highest

307 protein values in the postmortem BALF samples among the 5 treatment groups (Table 1).

308 Phospholipid values in BALF of lavaged rabbits also increased almost 10 -fold from 10.5 \pm 1.2 to

$30998.1 \pm 10.6 \mu \mathrm{g} / \mathrm{ml}$ after treatment with each of the 4 surfactant preparations or lipid alone.

310 Phospholipid content of the postmortem lavages of rabbits with HCl-induced ALI was 
311 comparable to that of the lavaged animals, although slightly, but statistically significantly, lower

312 in rabbits treated with synthetic peptide surfactants than in Infasurf or lipids alone.

313

\section{DISCUSSION}

315 The success of rescue therapy for chemical-induced ALI using synthetic surfactant with

316 advanced and robust SP-B and SP-C mimics represents a significant breakthrough, as previous

317 experiments have indicated only minimal or no improvement in lung function with animal-

318 derived and first generation synthetic surfactant preparations (Lamm \& Albert, 1990;

319 Brackenbury et al., 2001; Zimmermann et al., 2010; Lampland et al., 2014). Lamm \& Albert

320 (1990) tested Survanta, a modified natural surfactant based on a bovine lung extract, in rabbits

321 lungs after intratracheal injection of $\mathrm{HCl}$, but found no improvement in arterial oxygenation.

322 Brackenbury et al. (2001) treated rabbits pretreated with intratracheal $\mathrm{HCl}$ with natural ovine

323 surfactant, bovine lipid extract surfactant and recombinant SP-C surfactant (Venticute) and found

324 none of them effective. Recent studies by Zimmermann et al. (2010) and Lampland et al. (2014)

325 compared intratracheal instillation and aerosol delivery of KL4 surfactant (Surfaxin®, Discovery

326 Laboratories, Warrington, PA) with continuous positive airway pressure (CPAP) only in newborn

327 pigs with acute lung injury after $\mathrm{HCl}$ instillation. Both KL4 preparations improved survival, but

328 arterial oxygenation did not increase very much over the surfactant pretreatment values.

329 In a recent collaborative study with Tore Curstedt and Jan Johansson from the Karolinska

330 Institute in Sweden, we examined the in vivo activities of Mini-B, i.e. a 'truncated' 34-residue

331 predecessor of S-MB without the 7 amino-acid insertion sequence at the N-terminal (Waring et

332 al, 2005), and/or SP-C33 with synthetic lipids in preterm newborn rabbits (Almlén et al., 2010).

333 Treatment with either Mini-B or SP-C33 led to increased tidal and lung gas volumes, and

334 combination treatment with these surfactant protein mimics demonstrated an additive effect in

335 this validated animal model for neonatal respiratory distress. These results and the current data in 
336 lavaged and $\mathrm{HCl}$-treated young adult rabbits indicate that synthetic surfactants containing analogs

337 of both SP-B and SP-C may be superior to single-peptide surfactants in the treatment of RDS and 338 ALI/ARDS.

339 The BALF findings indicate that treatment with an advanced two-peptide synthetic

340 surfactant led to reduced protein values in the lavage fluid than those for single peptide synthetic

341 surfactant or animal-derived surfactant with both SP-B and SP-C. This finding suggests that a

342 more advanced and robust synthetic surfactant has the potential to diminish capillary-alveolar

343 protein leakage and thereby reduce surfactant inhibition.

344 Animal models have their advantages and limitations. In this study animals were studied

345 for 2 hours after surfactant treatment, but longer duration of the experiments (at least 6 hours)

346 might better correlate with clinical outcome in ALI/ARDS patients. Lung lavage and $\mathrm{HCl}$

347 instillation each result in significant hypoxemia without hemodynamic effects that are fairly

348 stable over at least the first 6-9 hours (Rosenthal et al., 1998). In our hands mortality in the lung

349 lavage model is less than the HCl-model, even though our primary goal of repeated lavages was

350 to decrease arterial $\mathrm{PO}_{2}$ to values $<100$ torr and we accepted a higher limit $\left(\mathrm{PaO}_{2}<200\right.$ torr $)$ after

$351 \mathrm{HCl}$ instillation because values $<80$ torr were associated with a quick demise. In fact, the average

$352 \mathrm{PaO}_{2}$ values after lung lavage were 53 torr (10\% of the original values) and 117 torr (22\% of

353 original values) after $\mathrm{HCl}$ treatment. Lung compliance corresponded with oxygenation, lung

354 lavage decreased lung compliance by $51 \%$ versus $39 \%$ after $\mathrm{HCl}$ treatment. These differences can

355 be explained by a lesser degree of capillary-alveolar protein leakage after lung lavage than acid

356 treatment that not only results in loss of active surfactant, but also leads to epithelial and

357 endothelial damage, lung hemorrhages and copious edema formation resulting in severe

358 surfactant dysfunction. 
361 As opposed to animal-derived (Infasurf) or first generation synthetic (Surfaxin or Venticute)

362 surfactant preparations, rescue therapy with a second generation synthetic (S-MB and SP-C33

363 UCLA in a synthetic three-lipid mixture) was highly effective in stabilizing and improving

364 oxygenation and lung compliance in rabbits with chemical-induced lung injury.

\section{5}

366 
368 Almlén A, Walther FJ, Waring AJ, Robertson B, Johansson J, Curstedt T. 2010. Synthetic

369 surfactant based on analogues of SP-B and SP-C is superior to single-peptide surfactants in

$370 \quad$ ventilated premature rabbits. Neonatology 98:91-99.

371 Bernard GR, Artigas A, Brigham KL, Carlet J, Falke K, Hudson L, Lamy M, Legall JR, Morris

372 A, Spragg R. 1994. The American-European Consensus Conference on ARDS. Definitions,

373 mechanisms, relevant outcomes, and clinical trial coordination. Am J Respir Crit Care Med

$374 \quad 149: 818-824$.

375 Brackenbury AM, Puligandla PS, McCaig LA, Nikore V, Yao LJ, Veldhuizen RA, Lewis JF.

376 2001. Evaluation of exogenous surfactant in HCL-induced lung injury. Am J Respir Crit Care

$377 \quad$ Med 163:1135-1142.

378 Brower RG, Fessler HE. 2011. Another "negative" trial of surfactant. Time to bury this idea? Am

$379 \quad J$ Respir Crit Care Med 183:966-968.

380 Chiumello D, Pristine G, Slutsky AS. 1999. Mechanical ventilation affects local and systemic

381 cytokines in an animal model of acute respiratory distress syndrome. Am J Respir Crit Care

$382 \quad$ Med 160:109-116.

383 Curstedt T, Johansson J, Persson P, Eklund A, Robertson B, Lowenadler B, Jornvall H. 1990.

384 Hydrophobic surfactant-associated polypeptides: SP-C is a lipopeptide with two

385 palmitoylated cysteine residues, whereas SP-B lacks covalently linked fatty acyl groups. Proc

$386 \quad$ Natl Acad Sci U S A 87:2985-2989.

387 Curstedt T, Calkovska A, Johansson J. 2013. New generation synthetic surfactants. Neonatology $388 \quad 103: 327-330$.

389 Czaja AS. 2007. A critical appraisal of a randomized controlled trial: Willson et al: Effect of

390 exogenous surfactant (calfactant) in pediatric acute lung injury (JAMA 2005, 293: 470-476).

$391 \quad$ Pediatr Crit Care Med 8:50-53. 
392 Dushianthan A, Cusack R, Goss V, Postle AD, Grocott MP. 2012. Clinical review: Exogenous

393 surfactant therapy for acute lung injury/acute respiratory distress syndrome - where do we go

394 from here? Crit Care 16:238.

395 Goerke J. 1998. Pulmonary surfactant: functions and molecular composition. Biochim Biophys

$396 \quad$ Acta 1408:79-89.

397 Goormaghtigh E, Cabiaux V, Ruysschaert J-M. 1990. Secondary structure and dosage of soluble

398 and membrane proteins by attenuated total reflection Fourier-transform infrared spectroscopy

399 on hydrated films. Eur J Biochem 193:409-420.

400 Gorguner M, Aslan S, Inandi T, Cakir Z. 2004. Reactive airways dysfunction syndrome in

401 housewives due to a bleach-hydrochloric acid mixture. Inhal Toxicol 16:87-91.

402 Ito Y, Goffin J, Veldhuizen R, Joseph M, Bjarneson D, McCaig L, Yao LJ, Marcou J, Lewis J.

403 1996. Timing of exogenous surfactant administration in a rabbit model of acute lung injury. $J$ $404 \quad$ Appl Physiol 80:1357-1364.

405 Johansson J, Curstedt T, Jornvall H. 1991. Surfactant Protein B: Disulfide bridges, structural 406 properties, and kringle similarities. Biochemistry 30:6917-6921.

407 Johansson J, Nilsson G, Stromberg R, Robertson B, Jornvall H, Curstedt T. 1995. Secondary

408 structure and biophysical activity of synthetic analogues of the pulmonary surfactant 409 polypeptide SP-C. Biochem J 307:535-541.

410 Johansson J. 1998. Structure and properties of surfactant protein C. Biochim Biophys Acta $411 \quad 1408: 161-172$.

412 Johansson J, Some M, Linderholm BM, Almlén A, Curstedt T, Robertson B. 2003. A synthetic

413 surfactant based on a poly-Leu SP-C analog and phospholipids: effects on tidal volumes and

414 lung gas volumes in ventilated immature newborn rabbits. J Appl Physiol 95:2055-2063.

415 Lamm WJ, Albert RK. 1990. Surfactant replacement improves lung recoil in rabbit lungs after 416 acid aspiration. Am Rev Respir Dis 142:1279-1283. 
417 Lampland AL, Wolfson MR, Mazela J, Henderson C, Gregory TJ, Meyers P, Plumm B, Worwa C,

418 Mammel MC. 2014. Aerosolized KL(4) surfactant improves short-term survival and gas

419 exchange in spontaneously breathing newborn pigs with hydrochloric acid-induced acute lung

$420 \quad$ injury. Pediatr Pulmonol 49:482-489.

421 Matthay MA, Ware LB, Zimmerman GA. 2012. The acute respiratory distress syndrome. J Clin $422 \quad$ Invest 122:2731-2740.

423 Maynard RM, Tetley TD. 2004. Bioterrorism: the lung under attack. Thorax 59:188-189.

424 Notter RH. 2000. Lung surfactants: Basic science and clinical applications. New York: Marcel 425 Dekker.

426 Pastrana B, Maulone AJ, Mendelsohn R. 1991. Fourier transform infrared studies of secondary 427 structure and orientation of pulmonary surfactant SP-C and its effect on the dynamic surface $428 \quad$ properties of phospholipids. Biochemistry 30:10058-10064.

429 Polin RA, Carlo WA; Committee on Fetus and Newborn. 2014. Surfactant replacement therapy 430 for preterm and term neonates with respiratory distress. Pediatrics 133:156-163.

431 Rosenthal C, Caronia C, Quinn C, Lugo N, Sagy M. 1998. A comparison among animal models 432 of acute lung injury. Crit Care Med 26:912-916.

433 Seurynck-Servoss SL, Brown NJ, Dohm MT, Wu CW, Barron AE. 2007. Lipid composition 434 greatly affects the in vitro surface activity of lung surfactant protein mimics. Colloids Surf B 435 Biointerfaces 57:37-55.

436 Spragg RG, Lewis JF, Walmrath HD, Johannigman J, Bellingan G, Laterre PF, Witte MC,

437 Richards GA, Rippin G, Rathgeb F, Häfner D, Taut FJ, Seeger W. 2004. Effect of

438 recombinant surfactant protein C-based surfactant on the acute respiratory distress syndrome. $439 \quad$ NEngl J Med 351:884-892. 
440 Spragg RG, Taut FJ, Lewis JF, Schenk P, Ruppert C, Dean N, Krell K, Karabinis A, Gunther A.

441 2011. Recombinant Surfactant Protein C-based Surfactant for Patients with Severe Direct

442 Lung Injury. Am J Respir Crit Care Med 183:1055-1061.

443 Tanaka Y, Takei T, Aiba T, Masuda K, Kiuchi A, Fujiwara T. 1986. Development of synthetic

$444 \quad$ lung surfactants. J Lipid Res 27:475-485.

445 Vandenbussche G, Clercx A, Curstedt T, Johansson J, Jornvall H, Ruysschaert JM. 1992.

446 Structure and orientation of the surfactant-associated protein C in a lipid bilayer. Eur $J$

447 Biochem 203:201-209.

448 Walther FJ, Hernández-Juviel J, Bruni R, Waring AJ. 1998. Protein composition of synthetic

449 surfactant affects gas exchange in surfactant-deficient rats. Pediatr Res 43:666-673.

450 Walther FJ, Gordon LM, Zasadzinski JA, Sherman MA, Waring AJ. 2000. Surfactant protein B $451 \quad$ and C analogues. Mol Genet Metab 71:342-351.

452 Walther FJ, Hernandez-Juviel J, Gordon LM, Waring AJ, Stenger P, Zasadzinski JA. 2005.

453 Comparison of three lipid formulations for synthetic surfactant with a surfactant protein B $454 \quad$ analog. Exp Lung Res 31:563-579.

455 Walther FJ, Waring AJ, Sherman MA, Zasadzinski JA, Gordon LM. 2007. Hydrophobic

456 surfactant proteins and their analogues. Neonatology 91:303-310.

457 Walther FJ, Waring AJ, Hernandez-Juviel JM, Gordon LM, Wang Z, Jung CL, Ruchala P, Clark

458 AP, Smith WM, Sharma S, Notter RH. 2010. Critical structural and functional roles for the N-

459 terminal insertion sequence in surfactant protein B analogs. PLoS One 5:e8672.

460 Waring AJ, Walther FJ, Gordon LM, Hernandez-Juviel JM, Hong T, Sherman MA, Alonso C,

461 Alig T, Braun A, Bacon D, Zasadzinski JA. 2005. The role of charged amphipathic helices in

462 the structure and function of surfactant protein B. J Pept Res 66:364-374.

463 White CW, Martin JG. 2010. Chlorine gas inhalation. Human clinical evidence of toxicity and 464 experience in animal models. Proc Am Thorac Soc 7:257-263. 
465 Whitsett JA, Weaver TE. 2002. Hydrophobic surfactant proteins in lung function and disease. $N$ $466 \quad$ Engl J Med 347:2141-2148.

467 Willson DF, Thomas NJ, Markovitz BP, Bauman LA, DiCarlo JV, Pon S, Jacobs BR, Jefferson 468 LS, Conaway MR, Egan EA; Pediatric Acute Lung Injury and Sepsis Investigators. 2005.

469 Effect of exogenous surfactant (calfactant) in pediatric acute lung injury: a randomized $470 \quad$ controlled trial. JAMA 293:470-476.

471 Zimmermann AM, Roberts KD, Lampland AL, Meyers PA, Worwa CT, Plumm B, Pacheco MC, 472 Wolfson MR, Mammel MC. 2010. Improved gas exchange and survival after KL-4 surfactant 473 in newborn pigs with severe acute lung injury. Pediatr Pulmonol 45:782-788. 


\section{Table 1 (on next page)}

Protein and phospholipid values in bronchoalveolar lavage fluid (BALF).

Protein and phospholipid values $(\mu \mathrm{g} / \mathrm{ml})$ in BALF obtained during the first lavage to induce surfactant deficiency and the first postmortem lung lavage in lavaged and $\mathrm{HCl}$-treated (postmortem BALF only) rabbits. Data are shown as mean \pm SEM. 


\begin{tabular}{|c|c|c|c|c|}
\hline \multirow[t]{2}{*}{ Surfactant } & \multirow{2}{*}{$\begin{array}{c}\text { Protein (ug/ml) } \\
\pm \text { SEM } \\
1^{\text {st }} \text { BALF }\end{array}$} & \multicolumn{3}{|c|}{ Phospholipids (ug/ml) \pm SEM } \\
\hline & & $\begin{array}{l}\text { Postmortem } \\
\text { BALF }\end{array}$ & $1^{\text {st }}$ BALF & $\begin{array}{l}\text { Postmortem } \\
\text { BALF }\end{array}$ \\
\hline \multicolumn{5}{|c|}{ Lung lavaged rabbits (n=7-8 per group) } \\
\hline $\begin{array}{l}\text { S-MB+SP-C33 } \\
\text { UCLA }\end{array}$ & $268 \pm 12$ & $2,124 \pm 130$ & $10.1 \pm 2.7$ & $100.5 \pm 17.8$ \\
\hline S-MB & $302 \pm 21$ & $2,358 \pm 65$ & $10.8 \pm 2.8$ & $96.3 \pm 33.0$ \\
\hline SP-C33 UCLA & $297 \pm 27$ & $2,503 \pm 146^{* *}$ & $9.4 \pm 1.9$ & $101.2 \pm 15.4$ \\
\hline Infasurf & $278 \pm 22$ & $2,648 \pm 137 * *$ & $11.2 \pm 2.8$ & $94.9 \pm 12.1$ \\
\hline Lipids alone & $285 \pm 26$ & $4,062 \pm 230^{*}$ & $11.4 \pm 2.4$ & $105.9 \pm 5.5$ \\
\hline \multicolumn{5}{|c|}{ HCl-instilled rabbits ( $n=8$ per group) } \\
\hline $\begin{array}{l}\text { S-MB+SP-C33 } \\
\text { UCLA }\end{array}$ & & $2,531 \pm 176$ & & $83.9 \pm 6.5$ \\
\hline S-MB & & $3,337 \pm 228 * *$ & & $87.2 \pm 5.4$ \\
\hline SP-C33 UCLA & & $3,203 \pm 235^{* * *}$ & & $98.3 \pm 2.0$ \\
\hline Infasurf & & $3,874 \pm 172^{* *}$ & & $103.9 \pm 3.5^{* * *}$ \\
\hline Lipids alone & & $4,623 \pm 224^{*}$ & & $105.9 \pm 2.7 * * *$ \\
\hline
\end{tabular}

*: $\mathrm{p}<0.01$ vs all other surfactant preparations

**: $\mathrm{p}<0.05$ vs S-MB+SP-C33 UCLA surfactant

***: $\mathrm{p}<0.05$ vs S-MB+SP-C33 UCLA and S-MB surfactant 


\section{Figure 1}

Surface activity of synthetic lung surfactants, clinical surfactant, and synthetic lipids only on the captive bubble surfactometer.

Minimum and maximum surface tension values are plotted for synthetic lipids with $3 \%$ (weight ratio) Super Mini-B (S-MB), 3\% SP-C33 UCLA or 1.5\% S-MB + 1.5\% SP-C33 UCLA, clinical surfactant (Infasurf), and synthetic lipids alone. Synthetic lipids are 5:3:2 (weight ratio) DPPC:POPC:POPG. Surface activity of S-MB surfactant, Infasurf and synthetic lipids alone have been reported previously (Walther et al., 2005 \& 2010). Data are shown as mean \pm SEM of $n=4$.

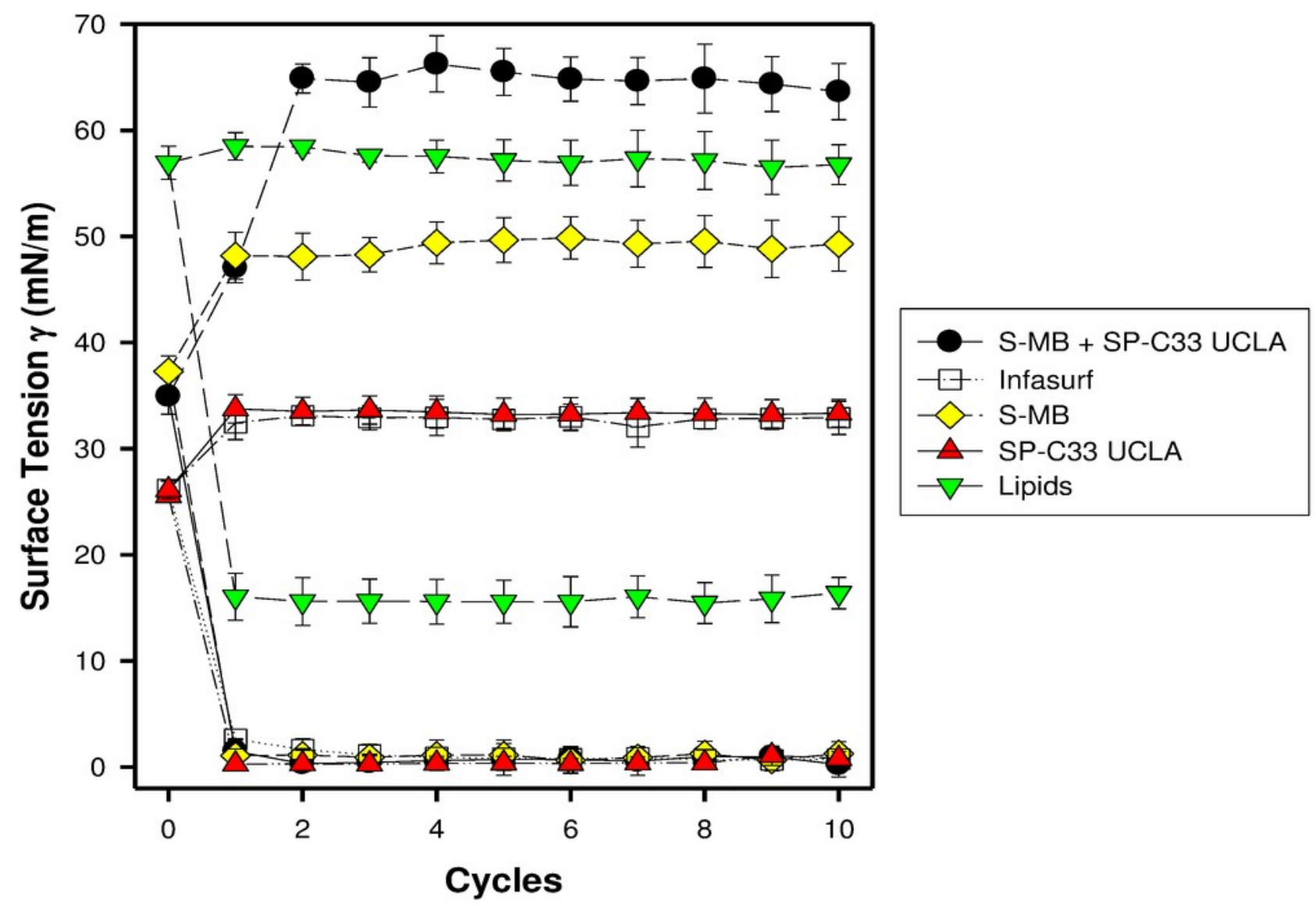




\section{Figure 2}

Arterial oxygenation and dynamic compliance in surfactant-treated, ventilated rabbits with ARDS induced by repeated in vivo lavage.

Arterial partial pressure of oxygen $\left(\mathrm{PaO}_{2}\right.$ in torr) and dynamic compliance $\left(\mathrm{ml} / \mathrm{kg} / \mathrm{cm} \mathrm{H}_{2} \mathrm{O}\right)$ are shown as a function of time for the 5 groups of 7-8 ventilated rabbits treated with experimental surfactant at time 0 , when $\mathrm{PaO}_{2}$ had dropped from $>500$ torr to $<100$ torr after standardized lung lavages. Rabbits treated with synthetic lung surfactants (synthetic lipids + $3 \%$ Super Mini-B [S-MB], 3\% SP-C33 UCLA or 1.5\% S-MB + 1.5\% SP-C33 UCLA) and clinical surfactant (Infasurf) as positive and synthetic lipids alone as negative control. Synthetic lipids are 5:3:2 (weight ratio) DPPC:POPC:POPG. From 90 min after surfactant treatment onwards, improvements in oxygenation and compliance for S-MB + SP-C33 UCLA surfactant differed significantly $(p<0.01)$ from the other surfactant preparations. Data are shown as mean \pm SEM of groups of 7-8 rabbits. 

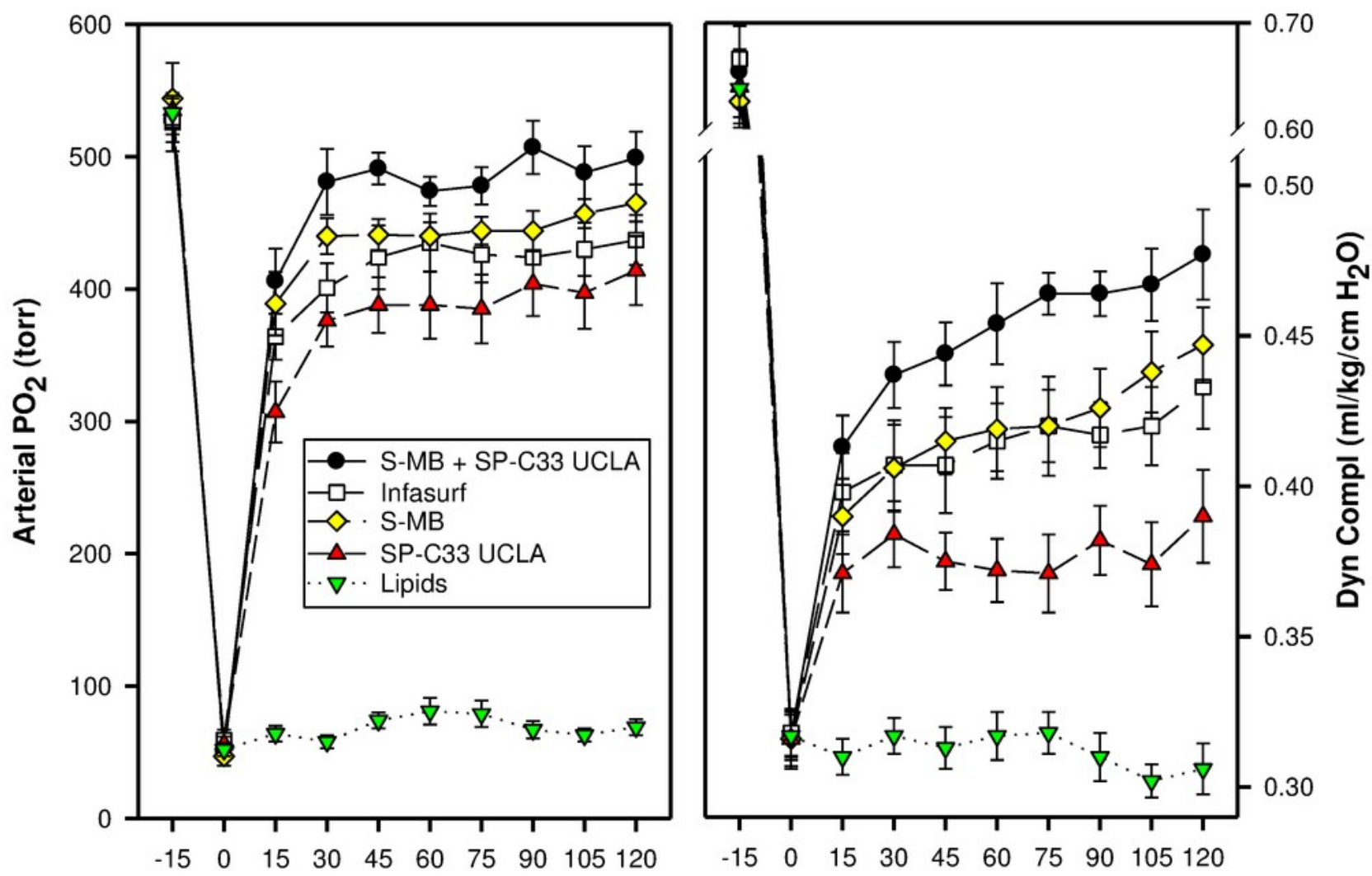

Time after surfactant instillation (min) 


\section{Figure 3}

Arterial oxygenation and dynamic compliance in surfactant-treated, ventilated rabbits with $\mathrm{ALI}$ induced by intratracheal instillation of $0.1 \mathrm{~N}$ hydrogen chloride $(\mathrm{HCl})$.

Arterial partial pressure of oxygen $\left(\mathrm{PaO}_{2}\right.$ in torr) and dynamic compliance $\left(\mathrm{mL} / \mathrm{kg} / \mathrm{cm} \mathrm{H}_{2} \mathrm{O}\right)$ are shown as a function of time for the 5 groups of 8 ventilated rabbits treated with experimental surfactant at time 0 , when $\mathrm{PaO}_{2}$ had dropped below $40 \%$ of the starting value after $\mathrm{HCl}$ instillation. Rabbits were treated with synthetic lung surfactants (synthetic lipids + $3 \%$ Super Mini-B [S-MB], 3\% SP-C33 UCLA, or 1.5\% S-MB + 1.5\% SP-C33 UCLA) and clinical surfactant (Infasurf) as positive and synthetic lipids alone as negative control. Synthetic lipids are 5:3:2 (weight ratio) DPPC:POPC:POPG. From 90 min after surfactant treatment onwards, improvements in oxygenation and compliance for S-MB + SP-C33 UCLA surfactant differed significantly $(p<0.01)$ from the other surfactant preparations. Data are shown as mean \pm SEM of groups of 8 rabbits. 


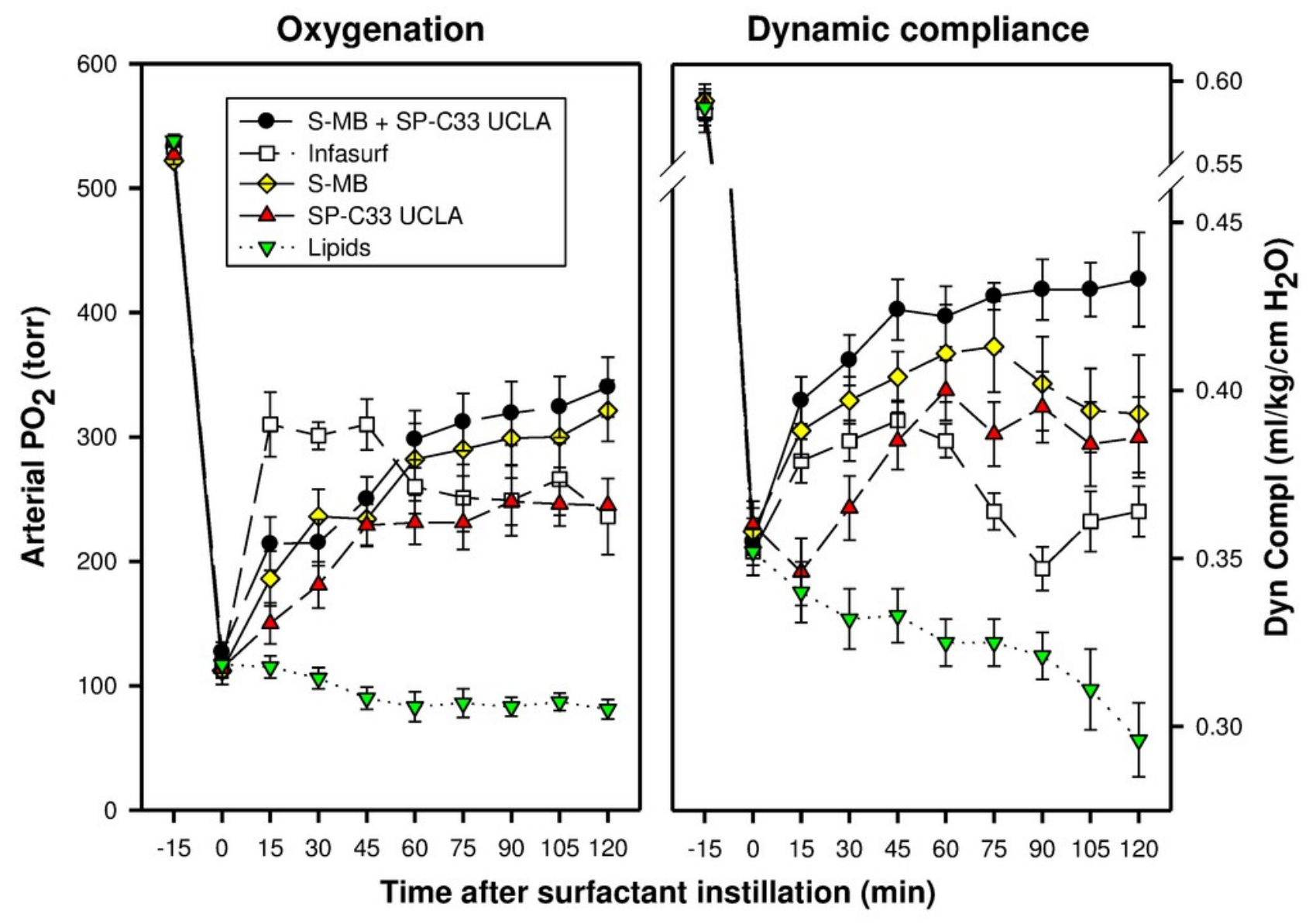

